\title{
DE 'BRAVE NEW WORLD' VAN MICHEL HOUELLEBECQ
}

\author{
Willy Coolsaet
}

De boeken van Michel Houellebecq kennen een enorm succes, ook in de Nederlandse vertaling. Ze wekken verontwaardiging en ze zijn verontrustend. Aan de hand van een interpretatie van Elementaire deeltjes uit $1999^{1}$ tracht ik een en ander te begrijpen.

\section{Kritiek van waaruit?}

Wie de draagwijdte van een kritiek wil vatten, doet er goed aan te letten op het voorgestelde alternatief - zelfs al zou het puur wensdenken zijn. Kritiek gebeurt immers altijd vanuit een bepaalde visie op mens en werkelijkheid en die treedt het duidelijkst aan het licht in het alternatief. Als het alternatief twijfelachtig, om niet te zeggen absurd blijkt te zijn, dan slaat dit op de visie terug. Wie droomt van absolute vrijheid, ziet niets anders dan dwang (dat blijkt misschien wel uit de manier waarop onder andere Jacques Ellul over de dwangmatige werking van het technologische bestel schrijft). Wie gelooft dat de realiteit één kluwen machtsverhoudingen is en toch nog blijft hopen op een ontsnapping, komt terecht in een conceptie van het leven als volstrekt individuele ontplooiing (Foucault). Wie gelooft in een utopische klasseloze maatschappij, met als voorwaarden een onmogelijke productiviteit, die moeiteloos alle behoeften moet bevredigen en de mens van alle inspanning moet verlossen, ziet overal uitbuiting, verslaving. Vanuit een dergelijke houding wordt haast de gehele werkelijkheid afgewezen. Er bestaat een 'dialectische' verhouding tussen de conceptie die men er over mens en realiteit op nahoudt en het gedroomde alternatief. Wie van een leven vol van een door niets gehinderd genot droomt, houdt er noodzakelijkerwijs een duister en triestig beeld van de huidige realiteit op na. Al te veel dingen worden dan als verkeerd, als ontoelaatbaar, als zinloos gebrandmerkt. Dan neemt men ook zo maar niet trends waar, maar viseert men een determinisme zonder enige ontsnappingsmogelijkheid. Ronald Commers ${ }^{2}$ - Herbert Marcuse achterna meent dat de seksualiteit nog steeds niet bevrijd is, vermits ze door de kapitalistische economie in een verwoestende richting geduwd wordt. Ware seksualiteit is tot op heden zelfs nog niet mogelijk, gezien het heersen van een economie van zwoegen en een door de economie zelf opgedrongen consumeren. Commers belijdt de utopische idee van een "wereld waarin weelde en materiële rijkdom de hoofden der mensen niet op hol brengen en hun lichamen niet verkrampen" (blz. 6). Dat is de Marcuse van de surplus-repressie, oorzaak van de heden door de kapitalistische economie georkestreerde seksualiteit. Ook al kan 
men er niet aan twijfelen dat de sociaal-economische context een grote invloed uitoefent, het is zeer de vraag of de relatie zo strikt is als Marx, Marcuse, Commers en vele anderen, waaronder Houellebecq stellen. Moet het 'ideale' leven als marcusiaanse play and display geduid worden, als een en al ontplooiing, op basis van een maatschappij van overvloed? Ik vrees dat het alternatief niet enkel irreëel, maar totaal onwenselijk is, het impliceert een mens die tot een armzalig verabsoluteerd genot gereduceerd wordt. Het boek van Michel Houellebecq Les particules élémentaires levert een mooie illustratie van dergelijke doorgedraaide kritiek ${ }^{3}$. Dat zullen we hier aantonen. Het sluitstuk van onze uiteenzetting zal de commentaar zijn op de Epiloog waarin het alternatief voor de hedendaagse maatschappij uit de doeken wordt gedaan.

Het is niet mijn bedoeling in te gaan op het enorme kabaal dat ontstaan is na het verschijnen van Les particules élémentaires - vooral protest van een zeker links en van zekere 'achtenzestigers', hoewel de oppervlakkigheid van de meeste recensies mij ergert. Ik wil veeleer de diepte peilen van Houellebecqs kritiek op onze maatschappij. We zullen begrijpen dat het hoofdthema van zijn boek 'seks en liefde' is - in feite bedoelt hij enkel seksueel genot - hoewel het thema van de menselijke sterfelijkheid even belangrijk is. Vooral het intrigerende van de excessieve reacties heeft me aangespoord om het boek te lezen en de lectuur tot het einde toe vol te houden. Dat laatste leek me niet evident. Het boek steekt namelijk vol halvelings pornografische passages die na enige tijd de keel beginnen uit te hangen. Men vraagt zich af hoe functioneel ze blijven. Een recensent zegt dat minstens een kwart van de roman uit dergelijke beschrijvingen bestaat. Het gehele boek wordt doorspekt met termen zoals pijpen, masturbatie, zelfbevrediging. Niet dat de meeste kritische linksen en achtenzestigers zich hierdoor laten afschrikken.

Hoewel ik tegenover Elementaire deeltjes negatief sta, moet ik bekennen dat het boek literair niveau en allure heeft; het is echter geen meesterwerk dat ooit tot de wereldliteratuur zal gaan behoren - hiervoor is het inhoudelijk te eng en te problematisch.

\section{Kritiek op de consumptiemaatschappij}

De verteller-ik zal vaak de verteller zeggen omdat we niet mogen stellen dat die met Houellebecq zo maar samenvalt - vangt als volgt aan: "Dit boek is vóór alles de geschiedenis van een mens, die het grootste gedeelte van zijn leven in WestEuropa leefde gedurende de tweede helft van de twintigste eeuw". De schrijver heeft het direct over eenzaamheid en verbittering, over ongelukkige, roerige tijden, armoede. "Gevoelens van liefde, tederheid en menselijke verbondenheid waren er nauwelijks meer; in hun onderlinge relaties gaven zijn tijdgenoten meestal blijk van onverschilligheid, of zelfs van wreedheid" (blz. 7). 
Houellebecq spreekt van een derde metafysische omwenteling waarvan een van de beide hoofdfiguren, Michel Djerzinski, de wegbereider is, na de eerste revolutie, de opkomst van het christendom, en de tweede, de opkomst van de moderne wetenschap en (voegen we toe) de moderne technologie ("de westerse technologische droom", blz. 37). In een cursief gezette bladzijde (einde proloog) heeft de schrijver het over "een geheel nieuwe heerschappij" die op komst is, over wat men vroeger onmogelijk achtte: een absolute, onbereikbare realiteit, hij spreekt van de bestemming die bereikt is: ze is een afscheid van de wereld van het isolement, om te baden in de onveranderlijke, vruchtbare vreugde van een nieuwe wet. Wat hij met dit alles - het alternatief - bedoelt, blijft vooreerst onduidelijk.

Direct lijken de personages hoofdzakelijk om seks bekommerd te zijn - en om de pijnlijke neergang van hun leven. Dit laatste - sterfelijkheid en eindigheid - is van cruciaal belang. Een aankondiging is dat als de tienjarige Michel zijn longen vult met de smaak van eeuwigheid de schrijver toevoegt: "De eeuwigheid van de kindertijd is een korte eeuwigheid, maar dat weet hij nog niet". En van Bruno luidt het dat hij als hij op zijn driewieler uit alle macht door de donkere gang trapte waarschijnlijk zijn hoogste aardse geluk gekend heeft.

De schrijver schetst een beeld van de hedendaagse maatschappij: massaconsumptie met bijbehorende verleidingsmarkt in een kapitalistische wereld, einde van het traditionele huwelijk, vrijheidsideaal, groei van de erotische consumptie, het bagatelliseren van abortus, euthanasie en zelfmoord, en vrije liefde of overspel (het gevolg van dit laatste is dat de twee hoofdfiguren Michel en Bruno halfbroers zijn), deze laatste moeilijk te verenigen met de opvoeding van de kinderen. Vergeten we new age, hippies en de communes "gebaseerd op seksuele vrijheid" niet (blz. 31) en verder de jongerencultuur "voornamelijk gebaseerd op seks en geweld" (blz. 75). Kortom een blijkbaar ontaarde maatschappij. Bruno wordt als kind aan zijn lot overgelaten. Hij heeft vroegtijdig een grote behoefte aan liefde, waaraan niet tegemoet wordt gekomen, als veertiger is hij een ontgoochelde, verbitterde, rijp voor de psychiater. Hij is, zou ik zeggen, niet tot liefde in staat, en zelfs nauwelijks tot seks, wellicht omdat hij niet weet wat liefde is. De "door lust verteerde" Bruno (blz. 69) stort zich in allerlei avontuurtjes. "Het voornaamste doel van zijn leven was van seksuele aard geweest; het was niet meer mogelijk van doel, te veranderen, wist hij nu" (blz. 69). "Daarin was Bruno een kind van zijn tijd" (blz. 69). Houellebecq spreekt van de voor onze tijd kenmerkende 'seksuele concurrentiestrijd'. Het is me dunkt alles fel opgeklopt.

\section{De mensheid een ramp}

Maar er is meer aan de hand. De schrijver wil niet alleen de huidige maatschappij op de korrel nemen. Eigenlijk vindt hij de menselijke realiteit 
zonder meer ondraaglijk. Zo ziet hij geen verschil tussen de brute natuur en de mensenmaatschappij. Hij schildert - trouwens in grote mate terecht - de natuur af als wreed, agressief, een smeerboel (blz. 38-39). Maar hij verwart natuur en leefwereld. Over het algemeen genomen, zegt hij "rechtvaardigde de woeste natuur een totale vernietiging, een universele holocaust - en de missie van de mens op aarde was waarschijnlijk die holocaust uit te voeren" (blz. 39). "Hij [de surveillant] koesterde geen enkele illusie omtrent het gedrag van de mens wanneer die niet meer aan het controlerende gezag van de wet onderworpen is" (blz. 49). "Vrijwel alle dierlijke samenlevingen functioneren op basis van een strikte hiërarchie [...] De posities in de hiërarchie worden over het algemeen bepaald door gevechtsrituelen" (blz. 51). De verteller brengt alweer de gedachte ongenuanceerd over op de leefwereld. Alsof de mens moet worden gedefinieerd als meedogenloos, wreedaardig, laat het dan zijn dat hij de enige diersoort is die echt sadistisch te werk kan gaan!

Houellebecq schetst een halvelings hobbesiaanse wereld met een state of nature waarin het leven van de mens solitary, poor, nasty, brutish and short is. Zoals bij Hobbes staat de natuurtoestand gelijk met de dierlijke aard van de mens, de natuurtoestand blijft ondergronds leven ook als er wetten ingevoerd worden (wat we zien in het wreedaardige pesterij die Bruno in het internaat moet ondergaan). De wetten ontstaan nadat later (in de ontwikkeling van de mensheid) mededogen, dit is, identificatie met het leed van de ander, ontsprongen is. Dat is bij Hobbes anders, volgens Hobbes leidt de vrees voor de gewelddadige dood tot de inrichting van een gemenebest.

Het wereldbeeld van de schrijver is uitgesproken biologisch en naturalistisch, de mens is blijkbaar niets anders dan een scheikundige machine. De verteller is een extreme objectivist. We zullen trouwens zien dat hij zijn alternatief voor de rotte wereld waarin hij vastzit, uitsluitend biochemisch onderbouwt. Hij wil de natuur van de mens grondig door elkaar schudden.

Er zijn meer elementen in het werk die niet herleid kunnen worden tot kritiek op de huidige maatschappij.

Vooreerst stelt hij de loskoppeling van seks en voortplanting voor. Ze kan moeilijk gezien worden als enkel een oplossing voor de problemen van de huidige consumptiemaatschappij. Hetzelfde geldt als de verteller vaders en zonen tegenover elkaar zet. "Ze naderden de toestand van rivaliteit, de natuurlijke toestand van mannen. Ze waren als beesten in één kooi die met elkaar vochten; die kooi was de tijd" (blz. 179). Er is ook de gedachte (blz. 180) dat seksualiteit een door en door slechte kracht is, "een nutteloze, gevaarlijke en regressieve functie" (blz. 286).

Houellebecqs aanval op het individu stijgt, vervolgens, ver uit boven wat we het huidige liberale of libertaire individualisme kunnen noemen. De verteller is tegen het individualisme, maar hij bedoelt tegelijk het individu zijn als dusdanig, en hij stelt dat gelijk met een grenzeloos egoïsme; "tot het einde toe 
zou er een individueel bewustzijn blijven bestaan in [de] afzonderlijke lijven" [van Bruno en Christiane] (blz. 215).

Bekijken we, tenslotte, de visie van de verteller op de loop van een mensenleven - alweer een universele, niet alleen aan onze maatschappij gebonden uitspraak. Een kind "leeft in volmaakte redelijkheid en het leeft in vreugde. Het is vol liefde, en zelf is het tevreden met de liefde die het als vanzelf ontvangt. Daarna loopt alles fout. Alles loopt onherstelbaar fout" (blz. 179). Het ligt aan de eindigheid en de sterfelijkheid van de mens. Dat is de basso continuo van de roman.

\section{Op weg naar het alternatief}

Maar wat is het gewicht van Houellebecqs kritiek? Blijkt niet reeds uit de toon en de taal van de verteller dat het alternatief zal blijven steken in wat het afwijst? Zo schemert iets van het alternatief door als Bruno over Brave New World van Aldous Huxley praat (blz. 167-168).

De steeds nauwkeuriger beheersing van de voortplanting, die uiteindelijk zal leiden tot een volledige loskoppeling van het geslachtelijk verkeer en tot reproductie van de menselijke soort in het laboratorium [...] Als gevolg daarvan de verdwijning van familierelaties, van de idee van vaderschap en afstamming. De opheffing, dankzij de farmaceutische vooruitgang, van het onderscheid tussen de verschillende leeftijden.

"De maatschappij die Brave New World beschrijft", zo wordt gezegd,

is heel gelukkig, alle tragiek en alle extreme gevoelens zijn eruit verdwenen. De seksuele vrijheid is totaal, niets staat de wellust en het genot meer in de weg. [...] Dat is precies de wereld waar we tegenwoordig naar streven, de wereld waarin we tegenwoordig zouden willen leven.

Het is je reinste hypocrisie, zo gaat het verder, om Brave New World als een totalitaire nachtmerrie te lezen. Huxley heeft onze tijd voorspeld: genetische beheersing, seksuele vrijheid, strijd tegen de ouderdom, vrijetijdsbeschaving. Brave New World is "voor ons een paradijs, in feite is het precies de wereld die wij proberen te bereiken, tot nu toe zonder succes".

Toch is Huxley niet tot volkomen inzicht gekomen. Hij heeft, zo zegt Bruno, het verband tussen de twee grote gevolgen - het rationalisme en het individualisme - van de materialistische en wetenschappelijke omwenteling verkeerd ingeschat. Het individualisme leidt namelijk, onder invloed van het steeds sterker wordende doodsbesef, tot vrijheid, zelfbewustheid, tot de noodzaak je te onderscheiden en beter te zijn dan de anderen. In onze samenleving, zegt Bruno, kan de strijd worden verzacht omdat economische 
concurrentie er geen bestaansreden meer heeft. Seksuele concurrentie evenmin, in een samenleving waarin voortplanting en seks volledig van elkaar zijn gescheiden. Maar, zegt hij, Huxley rekent buiten het individualisme. Hij heeft niet begrepen dat seks, eenmaal van de voortplanting gescheiden, niet zozeer blijft bestaan als lustprincipe, maar vooral als principe van narcistische differentiatie. De metafysische omwenteling waartoe de moderne wetenschap heeft geleid, brengt noodzakelijkerwijs individuatie, ijdelheid, haat en begeerte met zich mee. In de kern van de zaak is begeerte - in tegenstelling tot genot een bron van leed, haat en ongeluk.

De oplossing van de utopisten - van Plato tot Huxley, met inbegrip van Fourier bestaat erin de begeerte en het daarmee verbonden lijden uit te doven door een onmiddellijke bevrediging te organiseren. De erotisch-publicitaire maatschappij waarin wij leven, daarentegen, beijvert zich juist om de begeerte te organiseren, tot buitensporige proporties aan te wakkeren en de bevrediging ondertussen binnen de privé-sfeer te houden. Om de maatschappij te laten functioneren en de concurrentie te laten doorgaan, moet de begeerte blijven groeien, zich uitbreiden en het leven van de mensen verwoesten (blz. 172).

Voor Houellebecq is seksueel genot het enige dat het leven zinvol kan maken en dat tegelijk velen - alle vrouwen op latere leeftijd - verdoemt. Dat verklaart ook waarom men door zelfmoord afscheid van het leven neemt als men niet langer tot seksueel genot in staat is.

Houellebecq is blijkbaar uit op vrede, rust, op een leven zonder tragiek, zonder extreme gevoelens, maar met behoud van puur genot ${ }^{4}$. Maar dat lijkt op basis van zijn eigen beschrijvingen onzin te zijn. Alsof niet na de bevrediging de begeerte herrijst, en alsof het althans door Houellebecq in de verf gezette genot niet op grotere intensiteit, gevarieerdheid uit is, alsof het zich tevreden stelt met een enkele partner, alsof het dus niet zelf de begeerte ontsteekt. Maar in feite keert Houellebecq zich tegen prestatiedrang, en nog enkele andere verwante dingen: ijdelheid, haat, avontuur, verleiding, narcistische differentiatie. Hij vat ze wellicht allemaal samen in het begrip vrijheid en natuurlijk ook in het begrip begeerte. Voor de verteller is het blijkbaar een fijne zaak dat alle mensen gelijk zijn - in het zoeken naar genot wel te verstaan. De verschillen tussen de mensen zijn er teveel aan, Houellebecq vermag niet ook maar iets positiefs te zien in welke verschillen ook, misschien zelfs niet in geslachtelijke.

Afgezien van wat hij over verschillen denkt, zou men in zijn afwijzing kunnen inkomen: natuurlijk dat de opgesomde ondeugden niet alleen dodelijk zijn voor seksueel genot, ze zijn het ook voor menselijke relaties tout court. Maar Houellebecq gooit het kind met het badwater weg. Er is geen plaats meer voor liefde, voor vertrouwen en trouw, voor engagement, voor mede-leven. Men zou ten onrechte kunnen denken dat hij een pleidooi houdt voor tederheid, voor zich om de andere bekommeren, voor respect en waardering, zaken die verder reiken 
dan seksueel genot en trouwens tot een samen-leven aanzetten, tot een bij elkaar willen zijn en blijven, waarover Houellebecq in alle talen zwijgt (misschien op enkele kleine aanduidingen na in de vreemde relatie Bruno/Christiane). Het loopt alles uit op een verschrikkelijke reductie. Niet is in te zien hoe de deelnemers aan het seksuele genot niet eenzaam, geïsoleerd, achter blijven. Wat Houellebecq aanklaagt, reclame en commercialisering, mag dan inderdaad in onze samenleving werkzaam zijn - ze wegnemen moet in zijn ogen neerkomen op de bevrijding van het zuivere genot - tot een mens die nauwelijks menselijk genoemd kan worden omdat hij enkele essentiële dingen, waaronder vooral liefde, achter zich gelaten heeft.

\section{Het alternatief}

Pas in de Epiloog krijgt de lezer door wie de verteller is. Hier blijkt ook dat het boek is geschreven een heel eind in de eenentwintigste eeuw en dat 2009 de datum is waarop Michel Djerzinski zijn grote ontdekking gedaan heeft die is uitgelopen op de mogelijkheid tot onbeperkte replicatie van de mens (klonen). De bestaande mensheid moet plaatsmaken voor een nieuwe ongeslachtelijke en onsterfelijke soort die de individualiteit, het isolement en de verwording achter zich gelaten heeft (p. 330). De verteller zegt dat de grote godsdiensten er een inbreuk op de menselijke waardigheid in zagen, "die tot stand komt in de unieke betrekking van de mens tot zijn Schepper". Het boeddhisme is een uitzondering. Het is namelijk "voortgekomen uit de bewustwording van de drie hindernissen die ouderdom, ziekte en dood vormden". De verteller maakt de bedenking dat Boeddha, die weliswaar voor de weg van de meditatie gekozen heeft, een oplossing van technische aard niet zou hebben afgewezen (p. 331). Maar ook het humanisme verwierp het project in naam van de individuele vrijheid, de menselijke waarden en de vooruitgang - de grote waarden, zegt de verteller, in het materialistische tijdperk dat nu voorbij is. De verteller ziet in de halfslachtige, vage ideologie van new age een aanloop - "antwoord op een reëel lijden, dat voortkwam uit psychologische, ontologische en sociale onthechting" (p. 333) en tegelijk een "wil te breken met de twintigste eeuw, zijn immoralisme, zijn individualisme en zijn libertaire, antisociale karakter".

"Afschaffing van de geslachtelijke verschillen, die zo bepalend waren voor de menselijke identiteit", creatie van "een nieuwe met rede begaafde soort", "het einde van de seksualiteit als voortplantingswijze" maar "geenszins het einde van het seksuele genot - integendeel" (p. 334). Dat laatste wordt nog aangedikt. Men kan zich voorstellen dat de gehele huid van de mens voorzien kan worden van een gevoeligheid die tot op heden slechts over het oppervlak van de clitoris en de eikel verspreid zijn - "wat binnen het genotsysteem voor nieuwe, ongeëvenaarde erotische gewaarwordingen zou zorgen" (p. 334). De verteller merkt op dat "waarschijnlijk de meest diepgaande" kritiek (p. 335) was dat alle individuele 
dragers van dezelfde genetische code zouden zijn, en dat dus "een van de fundamentele elementen van de menselijke persoonlijkheid", de genetische individualiteit, zou verdwijnen (p. 335). Maar zo repliceert de verteller: deze individualiteit is juist "de oorzaak van het grootste deel van onze ellende". De omwenteling die gebeurd is, herstelt de gemeenschapszin en het gevoel voor het duurzame en het heilige (p. 336). "Naar het oordeel van de mensen is ons leven gelukkig. Inderdaad hebben we ons weten te bevrijden van de voor hen onontkoombare invloed van egoïsme, wreedheid en woede" [..] (p. 338). De individuele ijdelheid is verdwenen. "Op de mensen van het oude ras komt onze wereld over als een paradijs. Het gebeurt overigens wel eens dat we onszelf met iets van humor, dat wel - betitelen met de naam 'goden' die hen altijd zo dromerig stemde" (p. 338). De epiloog eindigt met een verwijzing naar die "deerniswekkende, vuige soort, nauwelijks van de aap te onderscheiden, die toch zoveel edele ambities met zich meedroeg. Die gekwelde, tegenstrijdige, individualistische en twistzieke soort met zijn grenzeloos egoïsme, die soms tot enorme geweldsuitbarstingen in staat was maar toch altijd in goedheid en liefde bleef geloven" (p. 339).

\section{Besluit}

Of Houellebecq zelf in het hier geschetste alternatief gelooft of niet, is niet beslissend. Want de lezer moet er het zijne bij denken. De terugslag op de kritiek is in beide gevallen van die aard dat de belang van het boek er sterk door afneemt. De onredelijkheid van het alternatief is al te groot. Maar het is vooral onwenselijk.

Men ziet hoe de individualiteit en de sterfelijkheid de grote boosdoeners zijn - wat op slag duidelijk maakt dat Houellebecq niet slechts de tweede helft van de vorige eeuw (dat dan misschien slechts een hoogtepunt moet worden genoemd) maar de mens als zodanig op de korrel neemt. Het individu is het individu in zijn verschil met andere individuen, in de eerste plaats het verschil van man en vrouw, en het familieverband (ouders en kinderen). En het is natuurlijk het individu dat sterft. Houellebecq kan met deze eindigheid niet leven. En als we in zijn alternatief niet kunnen geloven (wat me dunkt evident is) dan komt Houellebecqs boek op een absurd nihilisme neer. Het leven is onmogelijk. De verteller wijst op de volstrekt mislukte opvoeding van Michel en Bruno. Maar in plaats van voor een andere levenshouding te pleiten, schaft hij liever alle opvoeding - die toch in eerste instantie in het gezin gebeurt - af. Hij klaagt de liefdeloosheid aan, maar zet hij liefde in de plaats? Hoe zou dat kunnen vanuit zijn perspectief van puur genot - dat in feite ondanks zijn bedoeling puur individueel genot blijft?

Betekent dit dat de kritiek van Houellebecq nergens op slaat? Heel zeker niet. Hij klaagt terecht een zekere vrijheidsconceptie en een bepaald soort 
individualisme aan (die deze keer wel degelijk typisch zijn voor 'de tweede helft van de twintigste eeuw', ondanks het feit dat ze reeds oude wortels hebben) hoewel hij ze verkeerd inschat. Dat laatste kan ook niet anders want hij blijft in een hoge graad medeplichtig met wat hij afwijst. In plaats van vrijheid en individualisme (en egoïsme) had hij beter de trend naar 'vrije ontplooiing' vermeld - die zich voor hem ten onrechte beperkt tot seksuele ontplooiing, maar in feite meer en meer allerlei levensgebieden aantast). Niet de vrijheid is volgens mij de boeman met als alternatief een vreemd soort collectivisme, niet de individualiteit moet worden afgewezen, met als alternatief, een op zichzelf terugvallende genotzoekerij, maar een bepaald type verabsolutering van beide, die wordt aangedreven door datgene waar Houellebecq van droomt, opheffing van de eindigheid. Het individu is inderdaad niet alleen sterfelijk, het is ook pas individu in relatie tot andere individuen. Houellebecq wil de verschillen uitwissen, hij ziet hier alleen conflict, misschien op de verschillen na die nuances van genot kunnen opleveren. Hoewel dat niet in de epiloog die ons bezig houdt te lezen valt, zijn alle mensen in die zin gelijk dat er geen hechte relaties ontstaan; partnerruil, groepsseks, vluchtige ontmoetingen zijn blijkbaar implicaties van dit opzwepen van het genot (ik zou zeggen individueel genot, ondanks zijn wens dat het tegendeel waar zou zijn). Ik zeg implicaties, en inderdaad de zogezegde, zo noodzakelijk geachte bevrijding van de seks staat vijandig tegenover duurzaamheid en erkenning van een zekere conflictualiteit. De prijs die hiervoor moet betaald worden is evenwel al te hoog. Houellebecq is op de vlucht voor wat ik de constitutieve conflictualiteit van onze condition humaine noem. Het is nochtans zo dat de verwerping van die conflictualiteit vernietigend is. Wil men in staat zijn om een goed leven deelachtig te worden, dan moet men deze conflictualiteit erkennen. Dat is in de ogen van Houellebecq onmogelijk. Hij begrijpt niet dat al onze kansen op een gelukkig en zinvol leven op deze eindigheid steunen. De afwijzing ervan kan alleen tot een verschraald leven, tot eindeloze verveling leiden - zelfs als dat zou gebeuren midden seksueel genot.

\section{Noten}

${ }^{1}$ Michel Houellebecq, Elementaire deeltjes, Amsterdam, Arbeiderspers, 1999 oorspronkelijke titel: Les particules élémentaires, Parijs, Flammarion, 1998).

${ }^{2}$ Ronald Commers, De val van Eros. Over seksuele armoede vandaag, Antwerpen/Baarn, Houtekiet 2000.

${ }^{3}$ Commers legt zelf het verband met Houellebecq.

${ }^{4}$ Is het volgende Houellebecqs utopie? "Het was prettig te weten dat er geen onenigheid zou ontstaan, dat de seksuele problemen al waren opgelost; het was prettig te weten dat ieder zijn best zou doen, binnen de grenzen van zijn mogelijkheden, om de anderen genot te verschaffen" (blz. 234). Hij zegt dat het naturistenkamp van Le Cap d'Agde de geschikte plek was voor een humanistisch initiatief dat eenieders genoegen beoogt te 
maximaliseren zonder bij wie dan ook ondraaglijk geestelijk leed te veroorzaken. En dit gebeurt in hoofdzaak op basis van goede wil (blz. 236), zonder geweld, zelfs niet met de lichtste inbreuk op de hoffelijkheid (blz. 237). 